\title{
Surface Loading Effects on Orthophosphate Surface Complexation at the \\ Goethite/Water Interface as Examined by Extended X-Ray Absorption Fine Structure (EXAFS) Spectroscopy
}

\author{
ABDALA, Dalton Belchior ', NORTHRUP, Paul Andrew ${ }^{2}$, ARAI, Yuji ${ }^{3}$, \\ SPARKS, Donald Lewis ${ }^{4}$

\begin{abstract}
${ }^{1}$ Abdala, Dalton Belchior - Ph.D. graduate student, Plant \& Soil Sciences department, University of Delaware, Newark, DE - 19716, United States of America

${ }^{2}$ Northrup, Paul Andrew - Senior Research Scientist, Stony Brook University, National Synchrotron Light Source, Brookhaven National Laboratory, Upton, NY -
\end{abstract} \\ 11973 - United States of America
}

${ }^{3}$ Arai, Yuji - Assistant Professor, Department of Natural Resources and Environmental Sciences, University of Illinois at Urbana-Champaign, Urbana, IL 61801, United States of America

\footnotetext{
${ }^{4}$ Sparks, Donald Lewis - S. Hallock du Pont Chair, Department of Plant \& Soil Sciences and Delaware Environmental Institute, University of Delaware, Newark, DE 19716, United States of America
} 
* Corresponding author: Dalton Belchior Abdala, telephone: (Brazil) +55 198354

6682, daltonabdala@gmail.com , Brazilian Synchrotron Light Laboratory. Rua Giuseppe Maximo Scolfaro, 10000 - Campinas, ZIP 13 083-970, SP - Brazil 


\section{Abstract}

To investigate the effect of $\mathrm{P}$ surface loading on the structure of surface complexes formed at the goethite/water interface, goethite was reacted with orthophosphate at $\mathrm{P}$ concentrations of $0.1,0.2$, and $0.8 \mathrm{mmol} \mathrm{L}^{-1}$ at $\mathrm{pH} 4.5$ for 5 days. The $\mathrm{P}$ concentrations were chosen to ensure that $\mathrm{P}$ loadings at the surface would allow one to follow the transition between adsorption and surface precipitation. Extended X-ray Absorption Fine Structure (EXAFS) spectra were collected in fluorescence mode at the P K-edge at 2,150 $\mathrm{eV}$. The structural parameters were obtained through the fits of the sorption data to single and multiple scattering paths using Artemis. EXAFS analysis revealed a continuum among the different surface complexes, with bidentate mononuclear $\left({ }^{2} \mathrm{E}\right)$, bidentate binuclear $\left({ }^{2} \mathrm{C}\right)$ and monodentate mononuclear $\left({ }^{1} \mathrm{~V}\right)$ surface complexes forming at the goethite/water interface under the studied conditions. The distances for $\mathrm{P}-\mathrm{O}(1.51-1.53$ $\AA)$ and $\mathrm{P}-\mathrm{Fe}(3.2-3.3 \AA$ for bidentate binuclear and around $3.6 \AA$ for mononuclear surface complexes) shells observed in our study were consistent with distances obtained via other spectroscopic techniques. The shortest $\mathrm{P}-\mathrm{Fe}$ distance of $2.83-2.87 \AA$ was indicative of a bidentate mononuclear bonding configuration. The coexistence of different surface complexes or the predominance of one sorption mechanism over others was directly related to surface loading.

Keywords: phosphorus solid-state speciation, phosphorus surface complexation, phosphorus K-edge EXAFS, phosphorus retention mechanisms. 


\section{INTRODUCTION}

The combination of strong binding of phosphorus $(\mathrm{P})$ in soils, leading to its limited availability to plants, particularly, in highly weathered soils of the tropics, and the dependence of agriculture upon such soils for food production has motivated researchers to examine the sorption mechanisms of $\mathrm{P}$ in soils and soil components. From an environmental standpoint, issues surrounding excess $\mathrm{P}$, often due to the disposal of P-rich agricultural byproducts to agricultural lands, have also prompted researchers to address the chemical reactions controlling the reactivity and transport of this element ${ }^{1-5}$.

The adsorption phenomenon involving oxyanions and soil mineral oxides was originally thought to be characterized by an exchange reaction, which took place on the surface of soil minerals like $\mathrm{Fe}$ and $\mathrm{Al}$ (hydr)oxides. Early investigations aimed at understanding P bioavailability observed that phosphate exhibited some hysteresis and that behavior was attributed to the formation of more thermodynamically stable quasichemical entities or surface complexes. Elucidation of the surface complexes was speculative and inferred from multiple linear portions of the Langmuir plot, which were attributed to sites of varying reactivity ${ }^{6,7}$. Hingston et al. ${ }^{8-11}$ studied the sorption of several oxyanions, including $\mathrm{P}$, As and S, on goethite and gibbsite and concluded that the elemental selectivity of sorption was indeed due to specific sorption. It was only with the help of molecular-scale techniques that the lack of molecular descriptions of the surface complexes was fulfilled, bonding configurations corresponding to the different sorption mechanisms were first observed and chemisorption reactions were shown to be involved 12 
Over the past decades, solid-phase speciation studies of $\mathrm{P}$ have relied largely on the use of spectroscopic techniques, especially Fourier transform infra-red (FTIR) ${ }^{13-18}$ and Nuclear Magnetic Resonance (NMR) ${ }^{19-23}$ spectroscopies. A number of studies have been conducted to elucidate the sorption mechanisms and surface complexation/precipitation dependence on environmental conditions, particularly $\mathrm{pH}$ and P loading. Overall, and regardless of the technique employed, there seems to exist a consensus that the possible bonding configurations between phosphate and $\mathrm{Fe}$ and $\mathrm{Al}$ (hydr)oxides include bidentate binuclear $\left({ }^{2} \mathrm{C}\right)$ and monodentate mononuclear $\left({ }^{1} \mathrm{~V}\right)$ structures (Table 1). Nevertheless, interpretations of surface complex structures, such as whether monodentate or bidentate complexes form, and the conditions at which they form are not clear. In terms of goethite, Infrared (IR) studies have suggested that an innersphere bidentate binuclear surface complex may be the predominant mechanism at low $\mathrm{pHs}^{13,17}$ and low surface loading ${ }^{23}$. Kwon \& Kubicki ${ }^{24}$ employed MO/DFT calculations to model surface complexes and their findings corroborate the above studies. In a novel study employing NMR to address P sorption to Fe (hydr)oxides, Kim et al. ${ }^{22}$ studied the bonding mechanisms of $\mathrm{P}$ over a wide range of $\mathrm{P}$ concentration $(0.1-3 \mathrm{mM})$ and $\mathrm{pH}(3-$ 11) that encompasses most of the previous studies. They observed that a bidentate binuclear complex was formed regardless of environmental conditions. However, a monodentate mononuclear surface complex has also been suggested at low $\mathrm{pHs}{ }^{14}$ and at high P loadings ${ }^{23}$. IR studies on other Fe (hydr)oxides include the work on ferrihydrite by Arai $\&$ Sparks ${ }^{15}$, in which the authors have suggested that bidentate binuclear surface complexes that formed at $\mathrm{pH} 4$ to 6 were protonated and unprotonated complexes formed at $\mathrm{pH} \geq 7.5$. Elzinga \& Sparks ${ }^{16}$, working with hematite, observed the formation of 
bidentate binuclear structures at lower $\mathrm{pHs}$ and higher surface loadings in the $3.5-7.0 \mathrm{pH}$ range whereas, at the highest $\mathrm{pH}$ values studied (8.5-9.0), a monodentate mononuclear complex was present and its importance increased with increasing surface coverage at high $\mathrm{pH}$ values. It is worth pointing out that the controversies surrounding the accurate determination of sorption mechanisms are due to the lack of direct evidence together with the reliance of the molecular assignments on an analytical approach ${ }^{25,26}$. An additional aspect that most of the early studies fail to precisely address is the formation of surface precipitates ${ }^{15}$ i.e., three dimensional entities formed when further increases in sorbate concentration exceeds a monolayer coverage on the mineral surface. A vast literature on this topic indicates that surface loading has a pronounced effect on the continuum between surface complexation and surface precipitation on a number of soil minerals and environmentally important elements ${ }^{27-33}$. At high $\mathrm{P}$ concentrations, surface precipitation may be catalyzed leading to a new solid phase that is less readily dissolved or desorbed. According to Sparks ${ }^{34}$, surface complexation tends to dominate at low surface coverages. As surface coverage increases, nucleation is operational and results in the formation of distinct entities or aggregates on the surface. As surface loadings increase further, surface precipitation becomes the dominant mechanism.

Synchrotron-based X-ray absorption spectroscopy (XAS) has been extensively applied to model systems to resolve molecular-level sorption mechanisms of a number of soil contaminants $15,35,36$. These tools can greatly improve our understanding of $\mathrm{P}$ reactions in soils and provide predictions on an atomic/molecular basis of mechanisms of $\mathrm{P}$ retention on soil minerals. Such data are useful in the development of molecular sorption models if one aims to relate $\mathrm{P}$ speciation to $\mathrm{P}$ mobilization. Whereas the use of 
state-of-the-art techniques, such as XAS (XANES and EXAFS) can enhance our knowledge on the reaction processes that elements undergo in the environment, some limitations may constrain their widespread use. When it comes to EXAFS analysis of low-Z elements such as $\mathrm{P}$, fluorescence yield decreases with decreasing atomic number, which is reflected in the poor signal:noise. This ultimately hinders the collection of high quality data. In addition, in dilute samples, e. g., environmental samples, fluorescence attenuation is severely augmented especially in a dense, high- $Z$ matrix such as goethite.

It is noteworthy to mention that ${ }^{37-39}$ employed XANES to distinguish $\mathrm{P}$ adsorption from surface precipitation at mineral/water interfaces. However, in their studies, the authors relied on indirect observations to address the bonding configurations of the surface structures being formed on the mineral surface, namely, the full width at half maximum height (FWHM) concept and extended Hückel calculations. Therefore, to the best of our knowledge, our study is the first to employ EXAFS to collect direct information on the $\mathrm{P}$ sorption mechanisms formed at the mineral/water interface.

Accordingly, we combined a batch technique with EXAFS spectroscopy to examine the effects of surface loading and $\mathrm{pH}$ on the local atomic environment of sorbed $\mathrm{P}$ at the goethite/water interface.

\section{MATERIAL \& METHODS}

\subsection{Mineral Synthesis}

Goethite was synthesized according to the method of Schwertmann \& Cornell ${ }^{40}$. Briefly, $200 \mathrm{~mL}$ of $1 \mathrm{M} \mathrm{Fe}\left(\mathrm{NO}_{3}\right)_{3} \cdot 9 \mathrm{H}_{2} \mathrm{O}$ were added to a plastic flask with continuous 
stirring and then $360 \mathrm{~mL}$ of $5 \mathrm{M} \mathrm{KOH}$ were carefully added. Four L of DDI water were added and the mixture was thoroughly mixed for $30 \mathrm{~min}$. The flask was sealed with Scotch duct tape and placed in an oven set at $70{ }^{\circ} \mathrm{C}$ for 4 days. After the $4^{\text {th }}$ day, the supernatant solution was poured off and the goethite precipitate, which had settled to the bottom of the container, was washed with dialysis tubing for about one week until the electric conductivity matched that of the distilled deionized water $\left(\sim 0.95 \mu \mathrm{S} \mathrm{cm}^{-1}\right)$. The dialyzed mineral was transferred into $50 \mathrm{~mL}$ centrifuge tubes and centrifuged at 11000 rpm for $30 \mathrm{~min}$. The supernatant was removed with a syringe and the precipitate was freeze dried for approximately $60 \mathrm{~h}$. Finally, the material was softly ground in a mortar and stored in a polystyrene bottle.

The specific surface area of the goethite, determined by a three point BrunauerEmmett-Teller $\mathrm{N}_{2}$ gas adsorption isotherm, was $40.0 \pm 0.6 \mathrm{~m}^{2} \mathrm{~g}^{-1}$.

\subsection{Sorption Experiments}

Centrifuge tubes containing stock goethite suspensions of $20 \mathrm{~g} \mathrm{~L}^{-1}$ were placed in a rotating shaker set at $30 \mathrm{rpm}$ at $298 \mathrm{~K}$ and equilibrated in $50 \mathrm{mmol} \mathrm{L}^{-1} \mathrm{KCl}$ with the $\mathrm{pH}$ adjusted to 4.5 for $36 \mathrm{~h}$ prior to phosphate addition. The $\mathrm{pH}$ in the suspensions was monitored throughout the shaking period and adjusted to the target $\mathrm{pH}$ as needed by the addition of either $\mathrm{NaOH}$ or $\mathrm{HCl}$. Thereafter, an aliquot of the suspension was transferred to a new centrifuge tube to yield a goethite suspension of $2 \mathrm{~g} \mathrm{~L}^{-1}$, and a phosphate solution of $0.1,0.2$, and $0.8 \mathrm{mmol} \mathrm{L}^{-1}$ was added. This corresponded to surface coverages of $1.25,2.5$ and $10 \mu \mathrm{mol} \mathrm{m} \mathrm{m}^{-2}$. The tubes were shaken and $5 \mathrm{~mL}$ aliquots from each tube were sampled on the 5th day. 
The phosphate concentrations were carefully chosen to ensure a range of surface coverages. The reaction time, 5 days, was shown to be sufficient to ensure that the bulk of the added $\mathrm{P}(>95 \%)$ was associated with the surface.

\subsection{XAS Sample Preparation and Analysis}

Each sample was immediately filtered to pass through a $0.22 \mu \mathrm{m}$ nitrocellulose membrane filter and washed three times with $3 \mathrm{~mL}$ of $\mathrm{pH}$ adjusted $50 \mathrm{mmol} \mathrm{L}^{-1} \mathrm{KCl}$ to remove any entrained phosphate not associated with the surface. The cellulose membrane filter containing the mineral paste was sealed with 5-micron polypropylene XRF thin film (Ultralene ${ }^{\circledR}$ ) and stored moist in a sealed sample box at $6{ }^{\circ} \mathrm{C}$ until analysis. The samples were stored for no more than $24 \mathrm{~h}$ prior to analysis. Phosphorus K-edge spectra $(2,150$ eV) were collected at beamline X15B at the National Synchrotron Light Source (NSLS) at Brookhaven National Laboratory. The X15B sample chamber is a "hutch box" containing a $\mathrm{He}$ atmosphere at 1.001 atm positive pressure.

EXAFS spectra were collected in fluorescence mode with samples mounted at $45^{\circ}$ to the incident beam, using a liquid-nitrogen-cooled Canberra Ultra-Low-Energy Germanium detector positioned at $90^{\circ}$. X15B beamline optics consist of a collimating and harmonic-rejection mirror, a monochromator utilizing Si (111) crystals to tune energy, and a focusing mirror to gather approximately $5 \times 10^{11}$ photons $\mathrm{sec}^{-1}$ into a $1-\mathrm{mm}$ spot at the sample position. The fluorescence signal was normalized to incident beam intensity as measured using a windowless ionization chamber. XAS spectra were collected at photon energies between 2099 and $2750 \mathrm{eV}$ with a minimum step size of 0.1 $\mathrm{eV}$ across the edge and gradually increasing step sizes up to $6 \mathrm{eV}$ at $2750 \mathrm{eV}$. The 
collected spectra were processed using the Athena software in the computer package IFEFFIT $^{41}$. Six to ten individual spectra were averaged for each sample.

\subsubsection{EXAFS Data Analysis}

The averaged spectra were normalized to an atomic absorption of one, and the EXAFS signal was extracted from the raw data using linear pre-edge and a quadratic spline post-edge, followed by subtraction of background using the Autobk algorithm ${ }^{42}$. Data were converted from energy to photo electron momentum (k-space) and k-weighted by $\mathrm{k}^{2}$. Fourier transforms (FT) of the $\mathrm{k}^{2}$-weighted EXAFS were calculated over a $\mathrm{k}$-range of 2.0 to between 10.1 and 10.6 to obtain the R-space. The FT of the EXAFS was fit with the predicted neighbor paths by varying the number of coordinating atoms $(\mathrm{CN})$, their distance $(\Delta \mathrm{R})$, mean square displacement $\left(\delta^{2}\right)$ and passive electron reduction factor $\left(\mathrm{S}_{0}{ }^{2}\right)$ in order to obtain the best fit between the experimental and predicted spectra.

First shell $(\mathrm{P}-\mathrm{O})$ bond distances were obtained from the literature from crystallographic data and were used in the fit and fixed at these values for higher shell fitting. We fixed the $\mathrm{CN}$ of the first oxygen shell at 4 as the regular coordination environment of $\mathrm{PO}_{4}$ ions. Fits to second neighbor Fe shells were made by setting the degeneracy of each surface complex, $\mathrm{CN}=2$ for bidentate binuclear or $\mathrm{CN}=1$ for either bidentate mononuclear or mononuclear coordination, and fitting an amplitude factor describing the fraction of $\mathrm{P}$ in each configuration. One may argue about the method used to fit first and second coordination shells, that is, by setting the $\mathrm{CN}$ instead of floating it, as is standard practice. Indeed, floating $\mathrm{CN}$ was our first approach. However, the misfit between data and fit was large enough to consider the approach we used. As a matter of 
fact, constraining some parameters during fitting of EXAFS data is not unusual in the literature $59,64,65$. Yet, in order to address our fitting strategy, we tested our fits by varying coordination numbers upon finding a reasonable goodness of fit for a given fit performed to second coordination shells. Lastly, to make best use of the data we collected, we found it appropriate to set $\mathrm{CNs}$ for each coordination shell, fit the data and to rely on existing information from related techniques.

Spectra of an aqueous solution of $10 \mathrm{mmol} \mathrm{L} \mathrm{L}^{-1} \mathrm{KH}_{2} \mathrm{PO}_{4}$ at $\mathrm{pH} 4.5\left(\mathrm{P}_{(\mathrm{aq})}\right)$ was collected and fit to confirm the position of the multiple scattering (MS) within the $\mathrm{PO}_{4}$ tetrahedron. The inclusion of MS improved the fit in the $1.6-2.8 \AA$ region as strong MS within the $\mathrm{PO}_{4}$ tetrahedron was expected. We included three MS paths in our fits: namely three-legged $\mathrm{P}-\mathrm{O} 1-\mathrm{O} 2-\mathrm{P}$ triangular $\left(\mathrm{MS}_{1}\right)$, four-legged $\mathrm{P}-\mathrm{O} 1-\mathrm{PO} 2-\mathrm{P}$ non collinear $\left(\mathrm{MS}_{2}\right)$ and four-legged $\mathrm{P}-\mathrm{O} 1-\mathrm{P}-\mathrm{O} 1-\mathrm{P}$ collinear $\left(\mathrm{MS}_{3}\right)$ paths.

Several different models were employed to fit the MS path, including (i) correlating $\sigma^{2}$ MS to 2 times that of the single scattering (SS) path; and (ii) a direct correlation between $\sigma^{2} \mathrm{MS}$ and that of the SS path ${ }^{43}$.

\section{RESULTS \& DISCUSSION}

There have been a number of previous studies using spectroscopic techniques to characterize phosphate surface complexes forming on Fe(III)-, Al- and Ti (hydr)oxide mineral surfaces, including MO/DFT and ATR-FTIR, CIR-FTIR, NMR and XANES spectroscopies. Unlike IR spectroscopy, EXAFS analysis is insensitive to the protonation environment of surface complexes. Therefore, our discussion will be limited to the 
bonding configuration of the surface species. In terms of bonding configuration, the bidentate binuclear configuration seems to be the most favorable $\mathrm{P}$ sorption complex formed at the (hydr)oxides surface (Table $1 ;{ }^{12,44,45}$ ). Yet, what has not been established in the literature related to $\mathrm{P}$ bonding configurations at mineral surfaces are the environmental conditions which favor formation of a particular sorption complex mechanism. Additionally, the majority of the studies have employed NMR and IR techniques. There are no reports in the literature using EXAFS where detailed structural information, such as next nearest neighbor, bond distance and coordination numbers are reported. A list of relevant studies on $\mathrm{P}$ sorption mechanisms formed at mineral (hydr)oxides surfaces is shown in Table 1 and is aimed at assisting in the discussion of our results.

\subsection{P-EXAFS Spectra}

In this study, XANES data are not presented as differences in $\mu(E)$ among spectra are very subtle.Figure 1 shows the experimental Fourier Transform results of EXAFS data of goethite spiked with $\mathrm{P}$ at surface coverages of $1.25,2.5$ and $10 \mu \mathrm{mol} \mathrm{m}{ }^{-2}$ at $\mathrm{pH}$ 4.5. The R-space is a result of the Fourier transformation of the $\chi(k)$ function. The peaks shown in the experimental $\chi(k)$ spectra are related to the coordination shells formed between $\mathrm{P}-\mathrm{O}$ and $\mathrm{P}-\mathrm{Fe}$ and reflect the interatomic distances within the material. For all samples, the $\mathrm{E}_{0}$ ranged from -2.28 to $0.96 \mathrm{eV}$. The contributions of $\mathrm{O}$ were localized at $\mathrm{P}$ - O distances ranging from 1.51 to $1.53 \AA$ and MS dominates at $\sim 2.75$ to $2.78 \AA$. The $\mathrm{P}-$ Fe shells are indicative of the existence of three different bonding configurations between $\mathrm{P}$ and the goethite surface and will be treated separately in the following discussion. 
Figure 2 shows the $k^{2}$-weighted EXAFS spectra of $\mathrm{P}$ sorbed on goethite. The structural parameters obtained from the linear least-square fits are presented in Table 2. A fit was accepted whenever the R-factor value for a given Fourier transform part, reported either in Fourier transform magnitude, real (R) or back-transformed k-space data (q), was less than $6 \%$. That is, the misfit between data and best fit. Figure 4 and 5 show the Real (R) and (q) parts of the Fourier transform of P sorbed on goethite, respectively, at three different surface coverages, $1.25,2.5$ and $10 \mu \mathrm{mol} \mathrm{m}{ }^{-2}$.

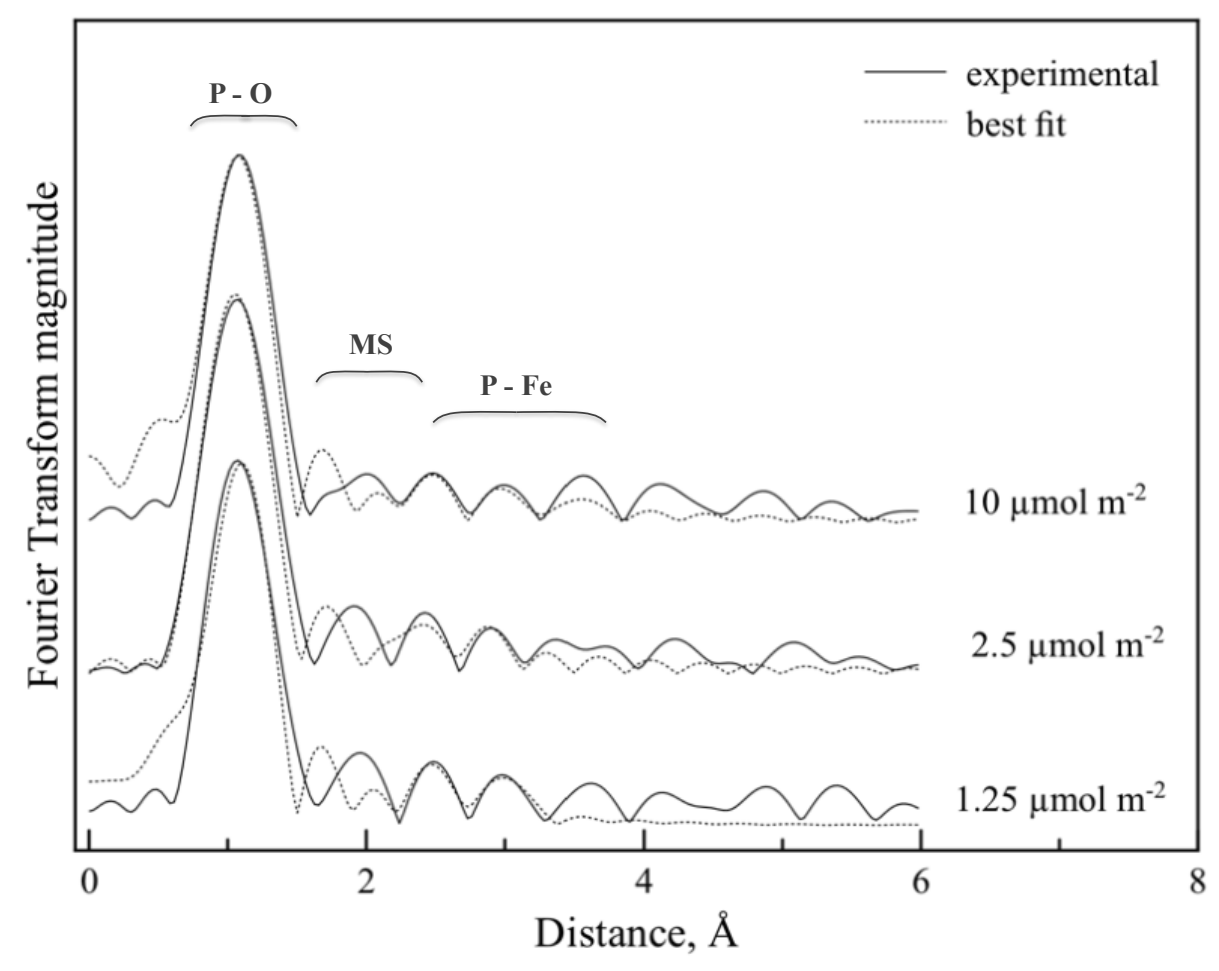

Figure 1. Experimental (solid line) and best fit (dashed line) Fourier transformed spectra of the phosphate surface complexes formed at the goethite/water interface at $\mathrm{pH}$ 4.5. A change in spectrum shape (R-space) followed by an increase in the phosphate loading indicates that the phosphate surface speciation changes with surface loading. Braces are intended to show the approximate region where the $\mathrm{P}-\mathrm{O}$, multiple scattering 
(MS) and $\mathrm{P}-\mathrm{Fe}$ shells most significantly contribute in radial distance in the Fourier transformed spectra.

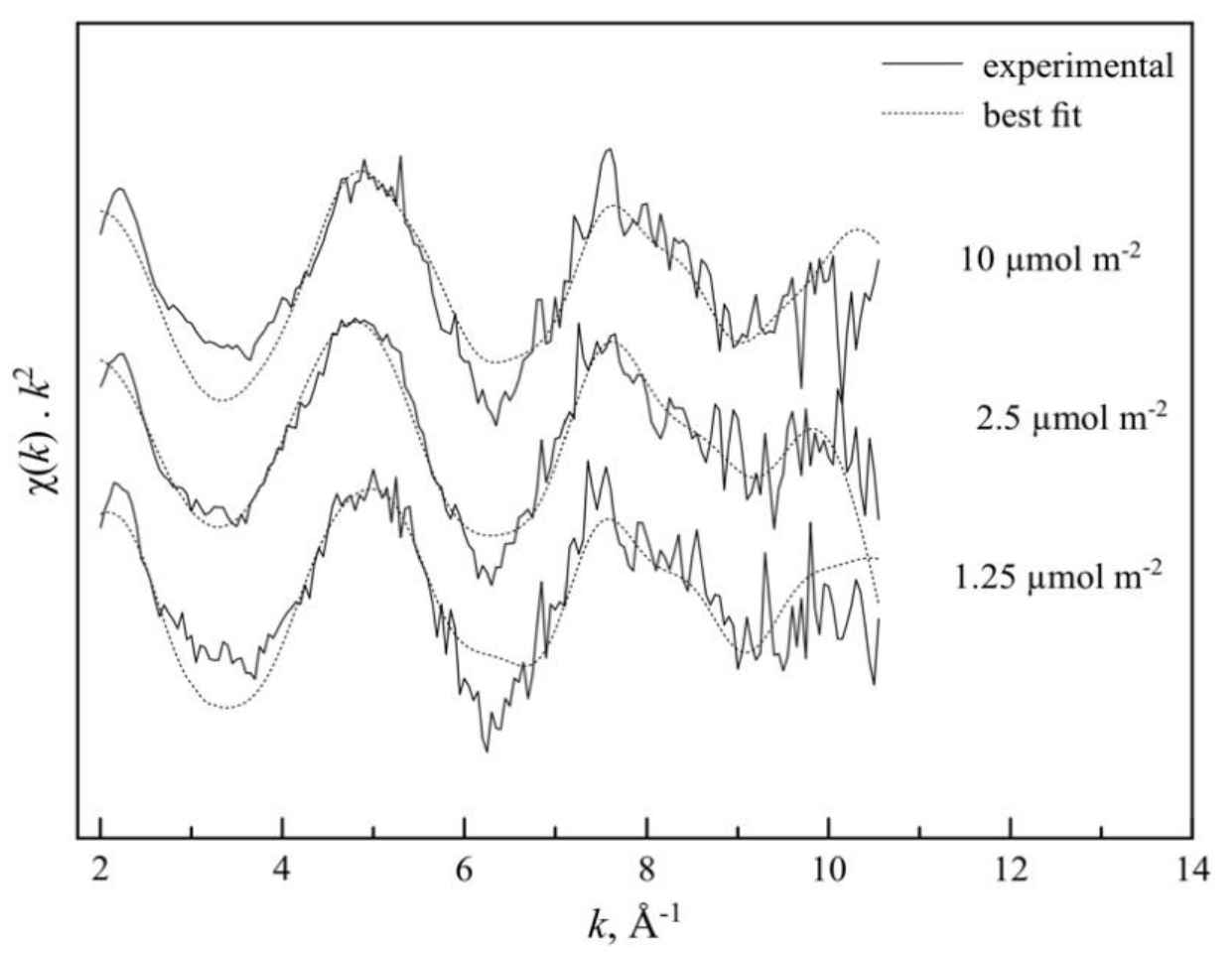

Figure 2. Experimental (solid line) and best-fit (dashed line) $k^{2}$-weighted backtransformed spectra of phosphate sorbed on goethite at $1.25,2.5$ and $10 \mu \mathrm{mol} \mathrm{m}^{-2}$ at $\mathrm{pH}$ 4.5. 


\subsection{Overall Formation of $P$ Surface Complexes at the Goethite/Water Interface}

We have identified the formation of three different phosphate surface complexes at the goethite/water interface, namely bidentate mononuclear $\left({ }^{2} \mathrm{E}\right)$, bidentate binuclear $\left({ }^{2} \mathrm{C}\right)$ and monodentate mononuclear $\left({ }^{1} \mathrm{~V}\right)$ surface complexes. Additionally, surface precipitates were also observed, particularly, at higher P loadings.

The shortest $\mathrm{P}-\mathrm{Fe}$ distances of 2.87 to $2.83 \AA$ are indicative of a bidentate mononuclear configuration between $\mathrm{P}$ and $\mathrm{Fe}$ at low and intermediate surface loadings, respectively. Intermediate $\mathrm{P}-\mathrm{Fe}$ distances of $3.27,3.3$ and $3.3 \AA$ were characteristic of a bidentate binuclear configuration between $\mathrm{P}$ and $\mathrm{Fe}$ at low, intermediate and high surface loadings, respectively. The most distant shell, $3.6 \AA$, was indicative of a linear configuration between $\mathrm{P}$ and $\mathrm{Fe}$. Table 2 shows the $\mathrm{P}-\mathrm{O}$ and $\mathrm{P}-\mathrm{Fe}$ bonding distances and corresponding P sorption mechanisms.

\subsection{Adsorption Complexes}

As indicated in Table 2, our results show that bidentate $\left({ }^{2} \mathrm{C}\right.$ and $\left.{ }^{2} \mathrm{E}\right)$ surface complexes are predominantly formed at low surface coverages and transition to monodentate configuration as surface coverage increases. This seems consistent with the literature that indicated that low surface coverages favor the formation of bidentate surface complexes $12,13,16,20,23,44-47$ and that the relative importance of bidentate binuclear species decreases as surface loading increases such that monodentate configuration would predominate at higher surface loadings ${ }^{13,23}$. However, on the basis of ATR-FTIR analysis, ${ }^{18,49}$ observed that P adsorbs mainly as bidentate complexes at 
high phosphate loadings and that monodentate surface complexes begin to be important at low phosphate loadings and at high pHs. This was ascribed to bidentate species locating more charge at the surface than monodentate species, producing a lower electrostatic repulsion between the adsorbed species in the 1-plane. Interestingly, the observation of ${ }^{18,49}$ is consistent with the behavior of arsenic in its pentavalent form $(\operatorname{As}(\mathrm{V}))$, an analog of phosphate, having similar chemical and geometric properties, and present as the ionic species, $\mathrm{H}_{2} \mathrm{AsO}_{4}{ }^{-}$and $\mathrm{H}_{2} \mathrm{PO}_{4}^{-}$, respectively, at the typical $\mathrm{pH}$ range in the environment.

Because there has not been any EXAFS study on orthophosphate bonding on mineral (hydr)oxides, we compared our results to studies relying on (i) MO/DFT and planewave/DFT calculations performed by ${ }^{23,24,61}$ on phosphate sorbed to Fe-oxides and on (ii) EXAFS of $\mathrm{As}(\mathrm{V})$ sorbed on mineral (hydr)oxides. Table 3 shows the $\mathrm{P}-\mathrm{O}$ and $\mathrm{P}$ - Fe bonding distances, surface complex distribution and corresponding bonding configurations of $\mathrm{P}$ on goethite as examined by EXAFS and obtained by MO/DFT and planewave/DFT calculations. On an average basis, our EXAFS observations were in good agreement with the calculated values, particularly for $\mathrm{P}-\mathrm{O}$, where interatomic distances varied within 0.05 to $0.1 \AA$. Likewise, the differences in $\mathrm{P}-\mathrm{Fe}$ bond lengths for a bidentate binuclear configuration were small, varying between 0.04 to $0.07 \AA$. P $-\mathrm{Fe}$ distances for a monodentate configuration showed the largest divergence among the two approaches, approximately $0.2 \AA$. With EXAFS studies on As(V), it was observed that $\mathrm{As}(\mathrm{V})$ can form three bonding configurations with mineral (hydr)oxides surfaces, similarly to what was observed in our study ${ }^{50,51}$. However, counter to what was observed by these authors, our results show a predominance of the bidentate corner-sharing $\left({ }^{2} \mathrm{C}\right)$ 
surface complex at lower surface coverages and a transition to edge-sharing $\left({ }^{2} \mathrm{E}\right)$ and monodentate corner-sharing $\left({ }^{1} \mathrm{~V}\right)$ as surface coverage increased to $10 \mu \mathrm{mol} \mathrm{m}{ }^{-2}$. A conceptual model depicting the surface loading effect on $\mathrm{P}$ surface complexation according to P-EXAFS analysis of sorption data from our study is shown in Figure 3.

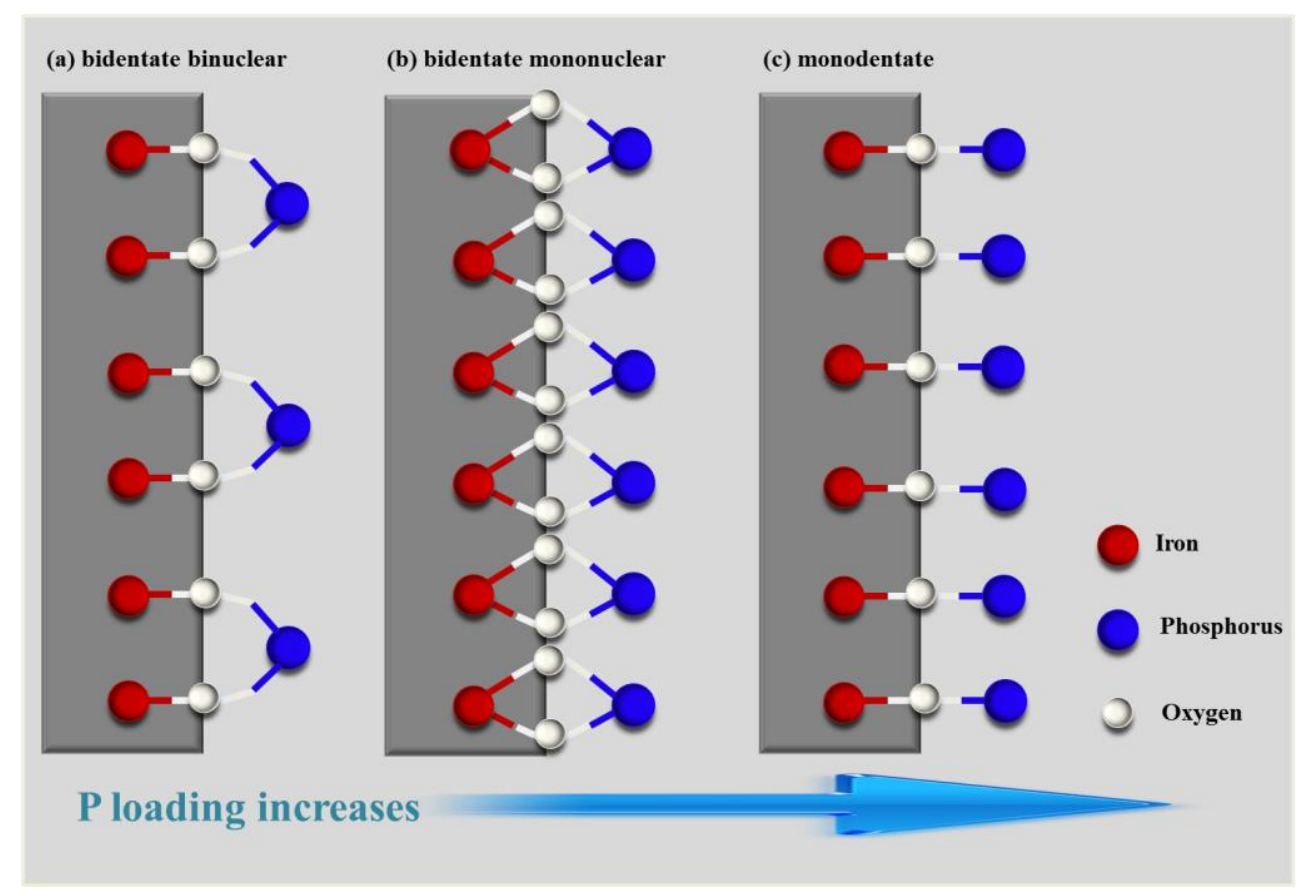

Figure 3. Conceptual model depicting the surface loading effect of $\mathrm{P}$ on surface complexation at the goethite/water interface as determined by P-EXAFS analysis of sorption data.

\subsubsection{Bidentate Mononuclear Configuration}

The shortest $\mathrm{P}-\mathrm{Fe}$ distances, 2.83 and $2.87 \AA$, represent an edge sharing between the phosphate tetrahedra and the Fe octahedra. Thus, the only possible configuration for such a short distance would be an edge-sharing bidentate mononuclear configuration $\left({ }^{2} \mathrm{E}\right)$. EXAFS spectroscopy has indicated that a bidentate mononuclear configuration $\left({ }^{2} \mathrm{E}\right)$ can be formed between tri-, tetra- and penta-valent metals and (hydr)oxide surfaces, such as 
$\mathrm{As}(\mathrm{V})$ on goethite ${ }^{49,50}, \mathrm{Se}(\mathrm{IV})$ on $\mathrm{HMO}^{51}, \mathrm{As}(\mathrm{III})$ on ferrihydrite and on hematite ${ }^{52}$ and As(III) on maghemite ${ }^{53}$ under different experimental conditions.

However, since the existence of a bidentate mononuclear surface complex between P and (hydr)oxide minerals has never been observed, we tried to rule out its existence by calculating it as forming a $120^{\circ}$ angle. In this case, the P-Fe bond distance would be 3.15 $\AA$. We also considered that MS contributions could be substantially affecting $\mathrm{R}$ at those distances, but this hypothesis was promptly discarded after MS from an aqueous orthophosphate sample (10 mmol L-1 as $\mathrm{KH}_{2} \mathrm{PO}_{4}$ at $\mathrm{pH}$ 4.5) showed MS contributions at around $~ 2.74 \AA$.

Furthermore, the $\mathrm{P}-\mathrm{Fe}$ distances observed in our study are comparable to those observed in the above-mentioned EXAFS studies, $2.83-2.87 \AA$ and $2.87-3.08 \AA$, respectively (reported distances include uncertainties associated with the measure).

\subsubsection{Bidentate Binuclear Configuration}

A bidentate binuclear configuration $\left({ }^{2} \mathrm{C}\right.$ ) of phosphate on (hydr)oxides has been shown to be the predominant sorption mechanism formed at lower surface coverages. In this study, the ${ }^{2} \mathrm{C}$ surface complex was present, although at different proportions, across the entire surface coverage range. The rationale for why ${ }^{2} \mathrm{C}$ predominates at lower surface coverages is that this configuration should be favored when the $\mathrm{Fe} / \mathrm{P}$ ratio is smaller than unity. It follows that at low $\mathrm{P}$ concentration, the sorption sites compete with the $\mathrm{PO}_{4}$ molecules at the same strength such that one $\mathrm{PO}_{4}$ molecule must equally satisfy as many sorption sites as possible. Therefore, ${ }^{2} \mathrm{C}$ forms first and because it is strongly bound to high affinity sorption sites, it has a large thermodynamic stability, thus remaining 
associated with the surface even as solution P concentration increases. In addition, at low pHs, i.e., $\mathrm{pH} \sim 4.5$, a higher positive surface charge induces a higher adsorption capacity for anions like phosphate, because more negative charge can be brought to the surface for a given change in electrostatic potential ${ }^{53}$.

Table 2 shows the surface complex distribution as a function of surface loading. Following the surface complex distribution across the loading range, one can observe that the overall percent distribution of ${ }^{2} \mathrm{C}$ remains constant $(\sim 50 \%)$ when the surface coverage increases by a factor of 2 .

\subsubsection{Monodentate Configuration}

Relatively few spectroscopic studies have reported P being attached to (hydr)oxide surfaces in a monodentate $\left({ }^{1} \mathrm{~V}\right)$ configuration (Table 1). The studies in which a ${ }^{1} \mathrm{~V}$ configuration has been observed were, in general, carried out employing P concentrations at relatively high surface coverages ${ }^{13,16}$. Whereas the $\mathrm{P}-\mathrm{Fe}$ distances for bidentate binuclear configuration are in good agreement with the work by ${ }^{23}$, who found $\mathrm{P}-\mathrm{Fe}$ distances varying between 3.22 to $3.26 \AA$, the $\mathrm{P}-\mathrm{Fe}$ distance for a monodentate configuration observed in our study was much larger, $~ 3.6 \AA$. Though, this is in agreement with the calculations performed by ${ }^{24}$, who found $\mathrm{P}-\mathrm{Fe}$ bond distances generally longer for either configuration, if $\mathrm{a} \geq 170^{\circ}$ angle is formed by $\mathrm{P}-\mathrm{O}-\mathrm{Fe}$, suggesting a P - Fe bond distance of around 3.6 A. EXAFS studies indicate that for $\mathrm{As}(\mathrm{V})$ these distances are generally in the order of 3.57 to $3.63 \AA^{49,54}$. Since $\mathrm{P}$ is a much lighter element than As, it is possible that the repulsion of $\mathrm{P}$ by the $\mathrm{Fe}$ atoms tend to maintain $\mathrm{P}$ as far apart from $\mathrm{Fe}$ as possible, thus $\mathrm{P}-\mathrm{O}-\mathrm{Fe}$ forms preferentially a linear 
structure when a monodentate configuration is formed. Alternatively, the $\mathrm{Fe}-\mathrm{O}$ bond distance may also be influenced by the repulsion and, accordingly, present a longer total $\mathrm{Fe}-\mathrm{P}$ distance.

\subsection{Environmental Significance of our Findings}

In the highly weathered agricultural soils of the tropics, $\mathrm{P}$ is arguably the major limiting factor for crop production due to the high sorption capacity of these soils together with P's strong binding to mainly Al- and Fe-(hydr)oxide soil minerals. On the other hand, over-application of $\mathrm{P}$ fertilizers, particularly via application of organic amendments, has led to the buildup of soil $\mathrm{P}$ to levels at which $\mathrm{P}$ loss potential can be significantly increased ${ }^{4,5}$. Addressing how $\mathrm{P}$ surface complexation (SC) is affected by environmental conditions such as surface loading in acidic tropical soils represents a true challenge in terms of analytical methods. This is especially true in view of the limitations imposed by the techniques that have traditionally been employed, e.g., FTIR, for which utilization is constrained under $\mathrm{pHs}$ lower than $4.5^{21}$ (which is a soil $\mathrm{pH}$ range commonly found under tropical conditions) and ${ }^{31} \mathrm{P}$ NMR analysis in Fe-rich soils due to $\mathrm{Fe}$ paramagnetism $^{20}$.

Our P-EXAFS results represent an advance over the analytical limitations imposed by the above-mentioned techniques and provide direct evidence on the molecular basis for the low $\mathrm{P}$ availability in acidic soils low in $\mathrm{P}$ as well as for the greater cycling potential of $\mathrm{P}$ in soils high in this element. In addition, the research shows the suitability of the EXAFS technique to study $\mathrm{P}$ surface complexation at mineral/water interfaces under conditions typically found in tropical soils, that is, at relatively low $\mathrm{P}$ 
concentrations $\left(2.5 \mu \mathrm{mol} \mathrm{L}^{-1}\right.$, i.e., $\left.77.5 \mathrm{mg} \mathrm{kg}^{-1}\right)$ and at low $\mathrm{pHs}$, as EXAFS is insensitivity to the later.

Our results indicated that $\mathrm{P}$ was rapidly ( $<5$ days) sorbed at the goethite surface, even at surface loadings above the $\mathrm{P}$ loadings predicted for monolayer coverage on goethite. Regardless of the $\mathrm{P}$ surface loadings employed in this study, $\mathrm{P}$ sorbed on goethite via a ligand exchange mechanism, that is, forming a quite stable surface complex. It was also observed that surface loading has a marked effect on surface complexation, which transitioned from bidentate binuclear into bidentate mononuclear or monodentate with increases in surface loading (Figure 3). This continuum of binding mechanisms corroborates the vast literature indicating the thermodynamic feasibility for the formation of more stable structures at low surface coverages, where $\mathrm{P}$ availability is constrained due to the much higher binding energy involved ${ }^{12,44-46}$. In most acidic soils, the available $\mathrm{P}$ pool associated with soil minerals is usually low and only a small fraction of sorbed $\mathrm{P}$ is readily desorbable, most likely from solid phases formed from recent additions of fertilizer P or physically sorbed phosphate by less energetic binding. Over fertilization of $\mathrm{P}$ may, therefore, enhance $\mathrm{P}$ availability and mobility due to formation of monodentate surface complexes, which have a less energetic character, and are favored at high surface coverages.

\section{AKNOWLEDGEMENTS}

The senior author gratefully acknowledges the receipt of a Delaware Environmental Institute (DENIN) graduate fellowship. The authors appreciate financial support from the U.S. National Science Foundation via Delaware EPSCoR. Support for this project was 
made possible by the Unidel Foundation and by Delaware EPSCoR with funds from the National Science Foundation Grant EPS-0814251. We also extend our thanks to the United States Department of Energy for providing us access to the National Synchrotron Light Source and for the technical support provided by the later. 
Table 1. Relevant studies on the $\mathrm{P}$ sorption mechanisms formed at mineral (hydr)oxide surfaces using MO/DFT, ATR-FTIR, CIR-FTIR, NMR and XANES spectroscopies.

\begin{tabular}{|c|c|c|c|c|}
\hline Surface complex & Technique & 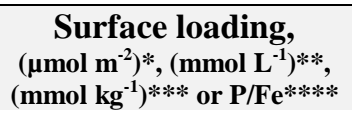 & Sorbent & Reference \\
\hline \multirow[t]{6}{*}{ Monodentate } & & & & \\
\hline & CIR-FTIR & high, $>17 * * * *$ & Goethite & Tejedor-Tejedor \& Anderson, $1990^{13}$ \\
\hline & ATR-FTIR & $0.4^{* *}$ & Goethite & Persson et al., $1996^{14}$ \\
\hline & & high, $\sim 0.5 * *$ & Hematite & Elzinga \& Sparks, $2007^{16}$ \\
\hline & $\mathrm{MO} / \mathrm{DFT}$ & high, $>1.5 *$ & Goethite & Rahnemaie et al., $2007^{23}$ \\
\hline & NMR & $0.1-100 * *$ & Boehmite & Kim \& Kirkpatrick, $2004^{20}$ \\
\hline \multirow[t]{15}{*}{ Bidentate } & & & & \\
\hline & CIR-FTIR & low, $<<\sim 0.2$ & Goethite & Tejedor-Tejedor \& Anderson, $1990^{13}$ \\
\hline & & initial conc. $\sim 5^{* *}$ & $\mathrm{TiO}_{2}$ & Connor \& McQuillan, $1999^{60}$ \\
\hline & ATR-FTIR & $0.38-2.69 *$ & Ferrihydrite & Arai \& Sparks, $2001^{15}$ \\
\hline & & initial conc. $\sim 0.06^{* *}$ & Goethite & Luengo et al., $2006^{17}$ \\
\hline & & $>\sim 0.2^{*}$ & Goethite & Antelo et al., $2005^{2}$ \\
\hline & & low $\sim 0.005 * *$ & Hematite & Elzinga \& Sparks, $2007^{16}$ \\
\hline & $\mathrm{MO} / \mathrm{DFT}$ & low $<1.5 *$ & Goethite & Rahnemaie et al., $2007^{23}$ \\
\hline & $\begin{array}{l}\text { ATR-FTIR, } \\
\text { planewave/ } \\
\text { DFT }\end{array}$ & $0.1 * *$ & Goethite & Kubicki et al., $2012^{61}$ \\
\hline & NMR & $0.1-150^{*}$ & $\begin{array}{c}\text { Boehmite and } \\
\gamma \text {-alumina }\end{array}$ & Kim \& Kirkpatrick, $2004^{20}$ \\
\hline & & $0.1-1.0 * *$ & Boehmite & Li et al., $2010^{21}$ \\
\hline & & $0.1-3.0 * *$ & $\begin{array}{l}\text { Akaganeite, } \\
\text { boehmite, } \\
\text { lepidocrocite }\end{array}$ & Kim et al., $2011^{22}$ \\
\hline & $\begin{array}{l}\text { NMR, } \\
\text { ATR-FTIR, } \\
\text { MO/DFT }\end{array}$ & $2.6-26^{*}$ & $\alpha-\mathrm{Al}_{2} \mathrm{O}_{3}$ & Li et al., 2013a ${ }^{62}$ \\
\hline & NMR & $0.15-150^{*}$ & $\begin{array}{c}\text { boehmite, } \\
\text { corundum, } \\
\text { gibbsite, } \\
\text { bayerite and } \\
\gamma \text {-alumina }\end{array}$ & Li et al., $2013 b^{63}$ \\
\hline & XANES & $750 * * *$ & Ferridydrite & Khare et al., $2007^{39}$ \\
\hline
\end{tabular}




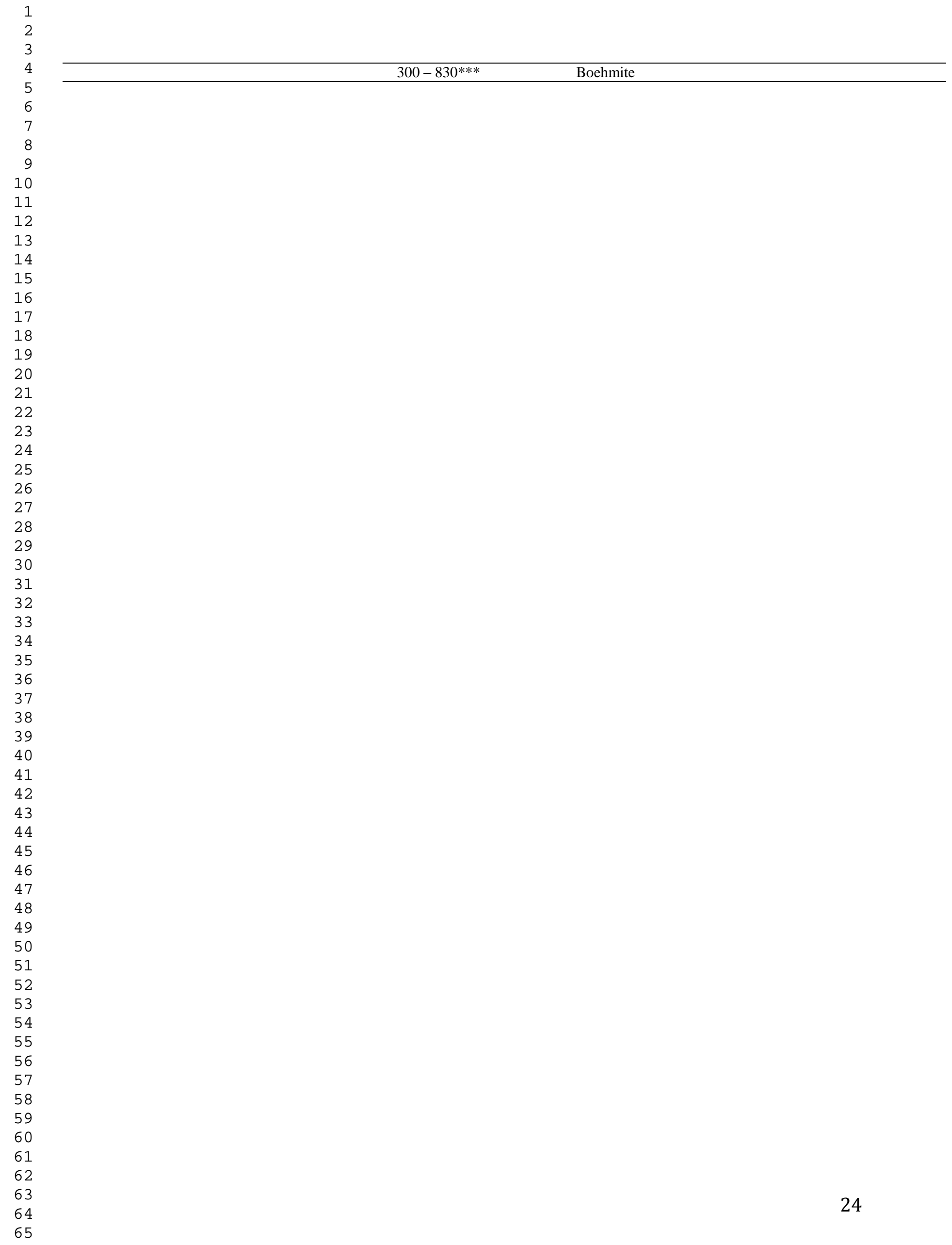


Table 2. $\mathrm{P}-\mathrm{O}$ and $\mathrm{P}-\mathrm{Fe}$ bonding distances, surface complex distribution and corresponding bonding configurations of $\mathrm{P}$ on 2 goethite at three different surface coverages.

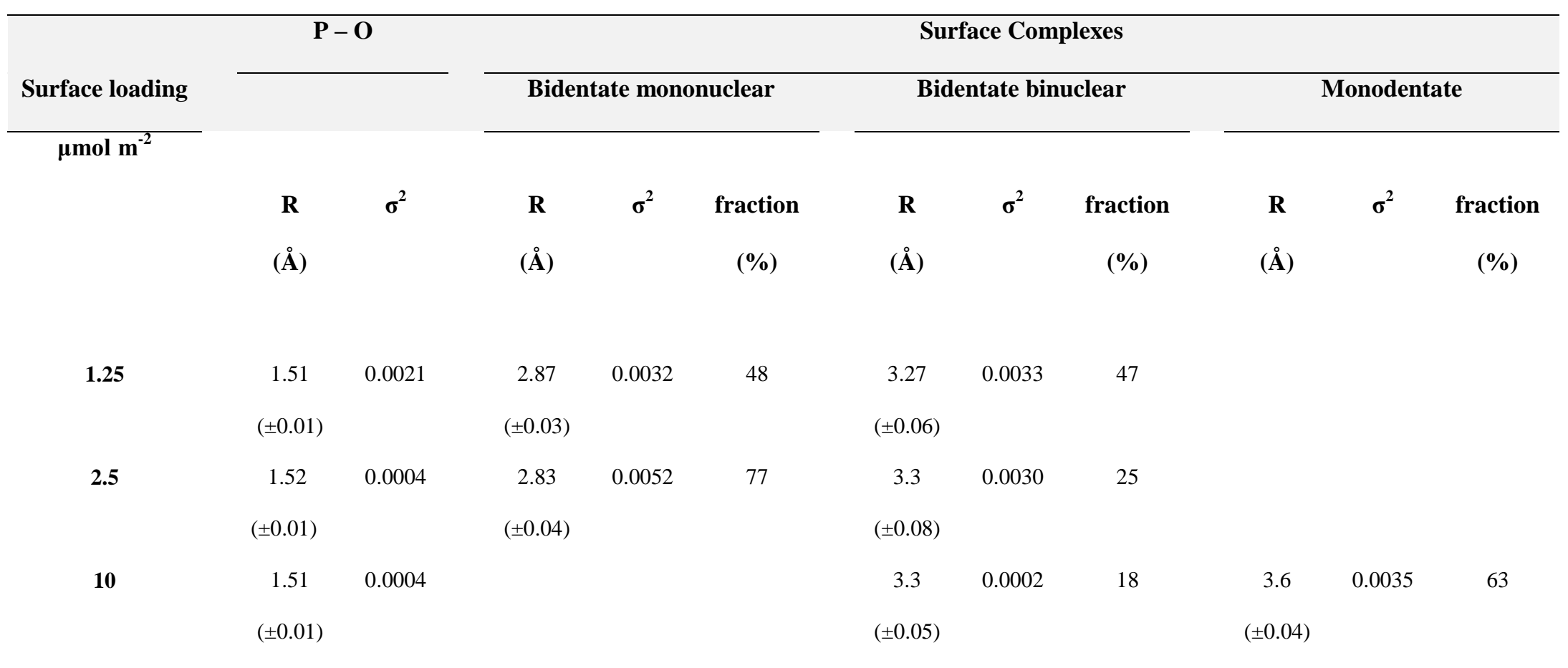

3 R: radial structure function (RSF); $\sigma^{2}:$ mean square displacement, ( ): uncertainties associated with parameter estimates 4 
5 Table 3. $\mathrm{P}-\mathrm{O}$ and $\mathrm{P}-\mathrm{Fe}$ bonding distances, surface complex distribution and 6 corresponding bonding configurations of $\mathrm{P}$ on goethite as examined by EXAFS and 7 obtained by MO/DFT calculations from Kwon \& Kubicki (2004), Rahnemaie et al. 8 (2007) and planewave/DFT calculations by Kubicki et al. (2012). The values shown on 9 the table correspond to the average of each individual value for a given surface complex.

\begin{tabular}{|c|c|c|c|c|c|c|c|c|}
\hline \multirow[t]{2}{*}{$\begin{array}{l}\text { Surface } \\
\text { complex }\end{array}$} & \multicolumn{2}{|c|}{ EXAFS $^{1}$} & \multicolumn{2}{|c|}{$\begin{array}{c}\text { Kwon \& Kubicki, } \\
2004\end{array}$} & \multicolumn{2}{|c|}{$\begin{array}{c}\text { Rahnemaie et al., } \\
2007\end{array}$} & \multicolumn{2}{|c|}{ Kubicki et al., 2012} \\
\hline & $\mathrm{P}-\mathrm{O}$ & $\mathrm{P}-\mathrm{Fe}$ & $\mathrm{P}-\mathrm{O}$ & $\mathrm{P}-\mathrm{Fe}$ & $\mathrm{P}-\mathrm{O}$ & $\mathrm{P}-\mathrm{Fe}$ & $\mathrm{P}-\mathrm{O}$ & $\mathrm{P}-\mathrm{Fe}$ \\
\hline Monodentate & 1.51 & 3.6 & 1.57 & 3.37 & 1.61 & 3.6 & 1.56 & $\begin{array}{c}3.42 \\
(3.25-3.55)^{3}\end{array}$ \\
\hline $\begin{array}{l}\text { Bidentate } \\
\text { binuclear }\end{array}$ & 1.51 & 3.28 & 1.59 & 3.21 & 1.6 & 3.24 & 1.56 & $\begin{array}{c}3.28 \\
(3.18-3.45)^{3}\end{array}$ \\
\hline $\begin{array}{c}\text { Bidentate } \\
\text { mononuclear }\end{array}$ & 1.52 & 2.85 & $\mathrm{NO}^{2}$ & $\mathrm{NO}^{2}$ & $\mathrm{NO}^{2}$ & $\mathrm{NO}^{2}$ & $\mathrm{NO}^{2}$ & $\mathrm{NO}^{2}$ \\
\hline
\end{tabular}

10 Bond distances represent an average for the three surface loadings in Table $2 .^{1}$

$11 \mathrm{NO}^{2}$ : Not observed.

12 The numbers in parenthesis indicate the range of $\mathrm{P}-\mathrm{Fe}$ bond lengths found by Kubicki et al., $2012 .^{3}$

13

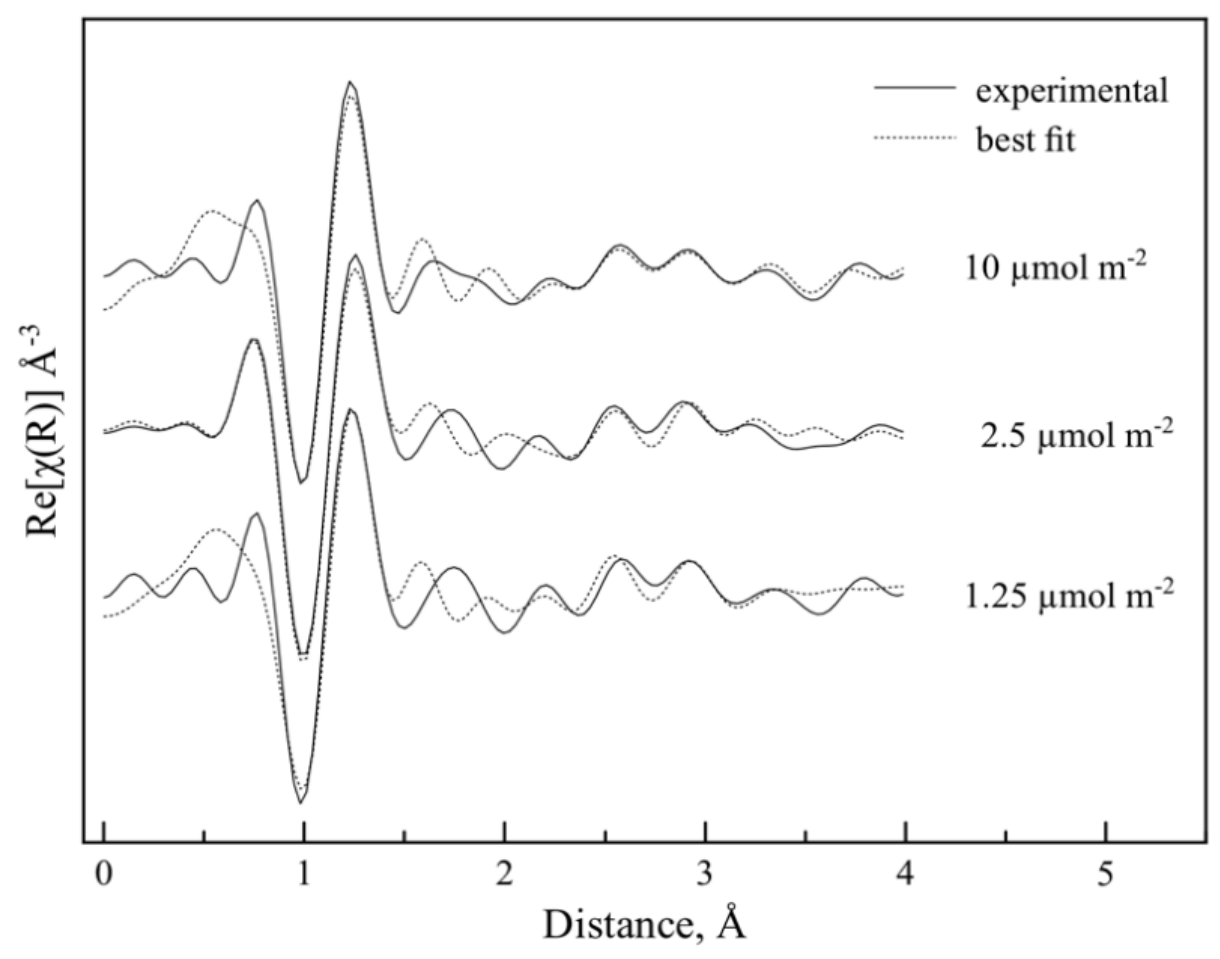

15 Figure 4. Real (R) part of the Fourier Transform of P sorbed on goethite at three different

16 surface coverages, $1.25,2.5$ and $10 \mu \mathrm{mol} \mathrm{m}^{-2}$. 


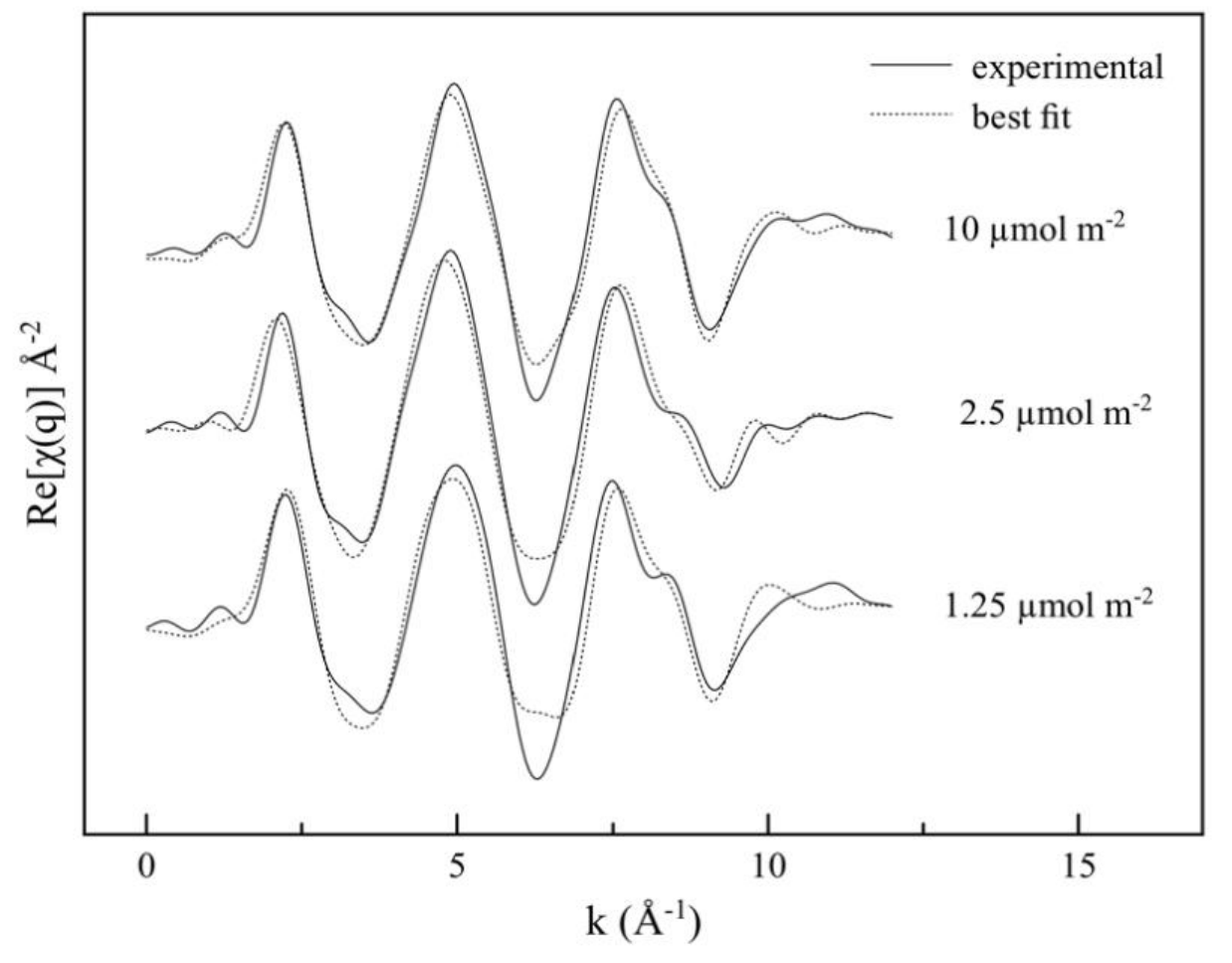

20 Figure 5. Real (q) part of the Fourier Transform of P sorbed on goethite at three different

21 surface coverages, $1.25,2.5$ and $10 \mu \mathrm{mol} \mathrm{m}^{-2}$.

22

23

24

25

26

27

28

29

30 


\section{REFERENCES}

(1) Novais, R. F. \& Smyth, T. J. Fósforo em solo e planta em condições

tropicais. Viçosa, MG, Universidade Federal de Viçosa, 1999. 399p

(2) Antelo, J., Avena, M., Fiol, S., Lopez, R., Arce, F. Effects of pH and ionic strength on the adsorption of phosphate and arsenate at the goethite-water interface. J. Colloid Interface Sci., 285:476-486, 2005

(3) Kruse, J. \& Leinweber, P. Phosphorus in sequentially extracted fen peat soils: A K-edge X-ray absorption near-edge structure (XANES) spectroscopy study. J. Plant Nutr. Soil Sc., 171:613-620, 2008 Phosphorus saturation of a tropical soil and related $\mathrm{P}$ leaching caused by poultry litter addition. Agr Ecosyst Environ., 162:15-33, 2012 application effects on phosphorus speciation, kinetics and distribution in highly weathered agricultural soils. Chemosphere, in press, 2014

51

Sci. Soc. Am. Proc., 20:471-475, 1956 
(7) Olsen, S. R. \& Watanabe, F. S. A method to determine a phosphorus

56

adsorption maximum of soils as measured by the Langmuir isotherm. Soil Sci. Soc.

57 Am. Proc., 21:144-149, 1957

58

59

(8) Hingston, F. J., Atkinson, R. J., Posner, A. M., Quirk, J. P. Specific

60 adsorption of anions on goethite. Congr. Soil Sci. Soc. $9^{\text {th }}$ (Adelaide), 669-678,

61 1968

62

63

(9) Hingston, F. J., R. J., Posner, A. M., Quirk, J. P. Competitive adsorption

64 of negatively charged ligands on oxide surfaces. Disc. Faraday Soc., 52:334-342,

65 1971

66

67

(10) Hingston, F. J., R. J., Posner, A. M., Quirk, J. P. Anion adsorption by

68 goethite and gibbsite. I. The role of the proton in determining adsorption envelops.

69 J. Soil Sci., 23:177-192, 1972

70

71

(11) Hingston, F. J., R. J., Posner, A. M., Quirk, J. P. Anion adsorption by goethite and gibbsite. II. Desorption of anions from hydrous oxide surfaces. J. Soil Sci., 25:16-26, 1974

74

75

(12) Parfitt, R. L., R. J. Atkinson, R. St. C. Smart. The mechanism of 76 phosphate fixation by iron oxides. Soil Sci. Soc. Am. J., 39:837-841, 1975 
(13) Tejedor-Tejedor, M. I. \& Anderson, M. A. The protonation of phosphate

79 on the surface of goethite as studied by CIR-FTIR and electrophoretic mobility.

$80 \quad$ Langmuir, 6:602-611, 1990

81

82

(14) Persson, P., Nilsson, N., Sjoberg, S. Structure and Bonding of

83 Orthophosphate Ions at the Iron Oxide-Aqueous Interface. J. Colloid Interface Sci., $84 \quad 177: 263-275,1996$

85

86

(15) Arai, Y. \& Sparks, D. L. ATR-FTIR spectroscopic investigation on

87 phosphate adsorption mechanisms at the ferrihydrite-water interface. J. Colloid

$88 \quad$ Interface Sci., 241: 317-326, 2001

89

90

(16) Elzinga, E. J. \& Sparks, D. L. Phosphate adsorption onto hematite: An in

91 situ ATR-FTIR investigation of the effects of $\mathrm{pH}$ and loading level on the mode of

92 phosphate surface complexation. J. Colloid Interface Sci., 308:53-70, 2007

93

94

(17) Luengo, C., Brigante’ M., Antelo, J., Avena, M. Kinetics of phosphate

95 adsorption on goethite: Comparing batch adsorption and ATR-IR measurements. J.

96 Colloid Interface Sci., 300:511-518, 2006

97 
98 (18) Antelo, J., Fiol, S., Pérez, C., Mariño, S., Arce, F., Gondar, D. López, R. 99 Analysis of phosphate adsorption onto ferrihydrite using the CD-MUSIC model. J. $100 \quad$ Colloid Interface Sci., 347:112-119, 2010

101

102

(19) Bleam, W. F., Pfeffer, P. E., Goldberg, S., Taylor, R. W., Dudley, R. A.

${ }^{31}$ P Solid-state Nuclear Magnetic Resonance study of phosphate adsorption at the

104 boehmite/aqueous solution interface. Langmuir, 7:1702-1712, 1991

105

106

(20) Kim, Y. \& Kirkpatrick, R. J. An investigation of phosphate adsorbed on 107 aluminium oxyhydroxide and oxide phases by nuclear magnetic resonance. Eur. J.

108 Soil Sci., 55:243-251, 2004

109

110

(21) Li, W., Feng, J., Kwon, K. D., Kubicki, J. D. Phillips, B. L. Surface

111 speciation of phosphate on boehmite $(\gamma-\mathrm{AlOOH})$ determined from NMR

112 spectroscopy. Langmuir, 26:4753-4761, 2010

113

114

(22) Kim, J., Li, W., Philips, B. L., Grey, C. P. Phosphate adsorption on

115 the iron oxyhydroxides goethite $(\alpha-\mathrm{FeOOH})$, akaganeite $(\beta-\mathrm{FeOOH})$,

116 and lepidocrocite ( $\gamma$-FeOOH): a ${ }^{31}$ P NMR Study. Energy Environ. Sci., 4:4298-

$117 \quad 4305,2011$

118 

distribution, and surface speciation of phosphate on goethite. Langmuir, 23:3680-

$121 \quad 3689,2007$

122

123

(24) Kwon, K. D. \& Kubicki, J. D. Molecular orbital theory study on surface 124 complex structures of phosphates to iron hydroxides: Calculation of vibrational 125 frequencies and adsorption energies. Langmuir, 20:9249-9254, 2004

(25) Arai, Y. \& Sparks, D. L. Phosphate reaction dynamics in soils and soil minerals: A Multiscale Approach, In Advances in Agronomy, 94: 135-179, 2007 studies on the competitive adsorption of arsenate and phosphate on ferrihydrite. J. 132 Colloid Interface Sci., 351:523-531, 2010

(27) Charlet, L. \& Manceau, A. X-ray absorption spectroscopic study of the sorption of $\mathrm{Cr}(\mathrm{III})$ at the oxide-water interface : II. Adsorption, coprecipitation, and 136 surface precipitation on hydrous ferric oxide. J. Colloid Interface Sci., 148: 443458,1992 
142 (29) Scheidegger, A. M., Lamble, G. M., Sparks, D. L. Spectroscopic 143 evidence for the formation of mixed-cation, hydroxide phases upon metal sorption 144 on clays and aluminum oxides. J. Colloid Interface Sci., 186:118-128, 1997

145

146 (30) Scheidegger, A. M., Strawn, D. G., Lamble, G.M., Sparks, D.L. The 147 kinetics of mixed Ni-Al hydroxide formation on clay and aluminum oxide minerals: 148 A time-resolved XAFS study. Geochim. Cosmochim. Acta, 62:2233-2245, 1998 149 150 (31) Ford, R. G. \& Sparks, D. L. The nature of Zn precipitates formed in the 151 presence of pyrophyllite. Environ. Sci. Technol. 34:2479-2483, 2000

152

153 (32) Roberts, D. R., Ford, R.G., Sparks, D. L. Kinetics and mechanisms of Zn 154 complexation on metal oxides using EXAFS spectroscopy. J. Colloid Interface Sci., $155 \quad 263: 364-376,2003$

156

157 (33) Nachtegaal, M. \& Sparks, D. L. Effect of iron oxide coatings on zinc 158 sorption mechanisms at the clay-mineral/water interface. J. Colloid Interface Sci. $159 \quad 276: 13-23,2004$

160 161 (34) Sparks, D. L. Environmental Soil Chemistry. Second Edition. Academic 162 Press, 2002, 368 pg. 163 
164 (35) Manning, B. A., Fendorf, S. E., Goldberg, S. Surface structures and 165 stability of arsenic(III) on goethite: Spectroscopic evidence for inner-sphere

166 complexes. Environ. Sci. Technol., 32:2383-2388, 1998

167

168 (36) Peak, J. D. \& Sparks, D. L. Mechanisms of selenate adsorption on iron 169 oxides and hyroxides. Environ. Sci. Technol., 36:1460-1466, 2002

170

171

(37) Hesterberg, D., Zhou, W., Hutchison, K. J., Beauchemin, S., Sayers, D.

172 E. XAS study of adsorbed forms of phosphate. J. Synchrotron Rad., 6:636-638, $173 \quad 1999$

174

175

(38) Khare, N., D. Hesterberg, and J. D. Martin. Investigating phosphate 176 surface precipitation in single and binary mixtures of Fe- and Al-oxide minerals using XANES. Environ. Sci. Technol., 39:2152-2160, 2005

178

179

(39) Khare, N., Martin, J. D., Hesterberg, D. Phosphate bonding configuration 180 on ferrihydrite based on molecular orbital calculations and XANES fingerprinting.

181 Geochim. Cosmochim. Acta, 71:4405-4415, 2007

182

183

(40) Schwertmann, U., Cornell, R. M. Iron Oxides in the Laboratory:

184 Preparation and Characterization; Wiley-VCH: Weinheim, Germany, 2000

185 
(41) Ravel, B. \& Newville, M. ATHENA and ARTEMIS: interactive graphical data analysis using IFEFFIT. J. Synchrotron Rad. 12:537-541, 2005 $\mathrm{x}$-ray-absorption fine structure of $\mathrm{Pb}$ : A comparison of theory and experiment. Phys. Rev. B Condens. Matter 47:14126-14131,1993

192

(43) Rouff, A. A., Natchegaal, M., Rabe, S., Vogel, F. X-ray absorption fine structure study of the effect of protonation on disorder and multiple scattering in phosphate solutions and solids. J. Phys. Chem. A., 113:6895-903, 2009

(44) Parfitt, R. L. Anion adsorption by soils and soil materials. Advances in Agronomy, 30:1-50, 1978

(45) Parfitt, R. L. The mechanism of phosphate fixation by iron oxides. Soil 201 Sci. Soc. Am. Proc., 39:837-841, 1975

(46) Parfitt, R. L., Atkinson, R. J. Phosphate adsorption on goethite ( $\alpha$ -

FeOOH). Nature, 264:740-742, 1976

(47) Parfitt, R.L., \& Russell, J. D. Adsorption on hydrous oxides. IV. 
(49) Grossl, P. R., Eick, M. J., Sparks, D. L., Goldberg, S., Ainsworth, C. C. 215 Arsenate and chromate retention mechanisms on goethite. 2. Kinetic evaluation 216 using a pressure-jump relaxation technique. Environ. Sci. Technol., 31:321-326, 1997

(50) Foster, A., Brown, G. E., Parks, G. A. X-ray absorption fine structure study of $\mathrm{As}(\mathrm{V})$ and $\mathrm{Se}(\mathrm{IV})$ sorption complexes on hydrous Mn oxides. Geochim. 221 Cosmochim. Acta, 67:1937-1953, 2003 analysis of arsenite adsorption onto two-line ferrihydrite, hematite, goethite, and lepidocrocite. Environ. Sci. Technol., 39:9147-9155, 2005

(52) Morin, G., Ona-Nguema, G., Wang, Y., Menguy, N., Juillot, F., Proux, 228 O., Guyot, F., Calas, G., Brown Jr., G. E. Extended X-ray absorption fine structure 229 analysis of arsenite and arsenate adsorption on maghemite, Environ. Sci. Technol., 42:2361-2366, 2008 
232 (53) Hiemstra, T. Surface complexation at mineral interfaces: Multisite and 233 Charge Distribution approach. (Ph.D. thesis), Wageningen University, 2010

234

235

(54) Waychunas G. A., Rea, B. A., Fuller, C. C., Davis, J. A. Surface

236 chemistry of ferrihydrite. 1. EXAFS studies of the geometry of coprecipitated and 237 adsorbed arsenate. Geochim. Cosmochim. Acta, 57:2251-2269, 1993

238

239

(55) Corey, R. B. Adsorption vs. coprecipitation, (1981) pp.161-182. In:

240 (Anderson, M. A. \& Rubin, A. J. eds.) Adsorption of Inorganics at Solid-Liquid 241 Interfaces, Ann Arbor Science, Ann Arbor Mich.

(56) Torrent, J. Activation energy of the slow reaction between phosphate and 244 goethites of different morphology. Aust. J. Soil Res., 29:69-74, 1990

(57) Dzombak, D. A., \& Morel, F. M. M. Surface Complexation Modeling: Hydrous Ferric Oxide. Wiley-Interscience, 1990. New York, 393 pp. 
253 (59) Arai, Y., Elzinga, E. J., Sparks, D. L. X-ray absorption spectroscopic 254 investigation of arsenite and arsenate adsorption at the aluminum oxide-water 255 interface. J. Colloid Interface Sci., 235:80-88, 2001

256

257

(60) Connor, P. A. \& McQuillan, A. J. Phosphate adsorption onto $\mathrm{TiO}_{2}$ from 258 aqueous solutions: $\square$ an in situ internal reflection infrared spectroscopic sudy. 259 Langmuir, 15:2916-2921, 1999

260

261

(61) Kubicki, J. D.; Paul, K. W.; Kabalan, L.; Zhu, Q.; Mrozik, M. K.; 262 Aryanpour, M.; Pierre-Louis, A.; Strongin, D. R. ATR-FTIR and density 263 functional theory study of the structures, energetics, and vibrational spectra of 264 phosphate adsorbed onto goethite. Langmuir, 28:14573-14587, 2012

265

266

(62) Li, W., Andro-Marc Pierre-Louis, A. M., Kwon, K. D., Kubicki, J. D., 267 Stronginc, D. R., Phillips, B. L. Molecular level investigations of phosphate 268 sorption on corundum $\left(\alpha-\mathrm{Al}_{2} \mathrm{O}_{3}\right)$ by ${ }^{31} \mathrm{P}$ solid state NMR, ATR-FTIR and quantum 269 chemical calculation. Geochim. Cosmochim. Acta, 107:252-266, 2013

270

271

(63) Li W., Feng, X., Yan, Y., Sparks, D. L., Phillips, B. L. Solid state NMR 272 spectroscopic study of phosphate sorption mechanisms on aluminum 273 (hydr)oxides. Environ. Sci. Technol., 15: 8308-8315, 2013

274 
275 (64) Bostick, B. C. \& Fendorf, S. E. Arsenite sorption on troilite (FeS) and 276 pyrite $\left(\mathrm{FeS}_{2}\right)$. Geochim. Cosmochim. Acta, 67:909-921, 2003

(65) Sherman, D. \& Randall, S. R. Surface compelxation of arsenic(V) to iron((III) (hydr)oxides: structural mechanisms from ab initio molecular geometries and EXAFS spectroscopy. Geochim. Cosmochim Acta, 67:4223-4230, 2003

\section{Table of Contents Graph (TOC Art):}
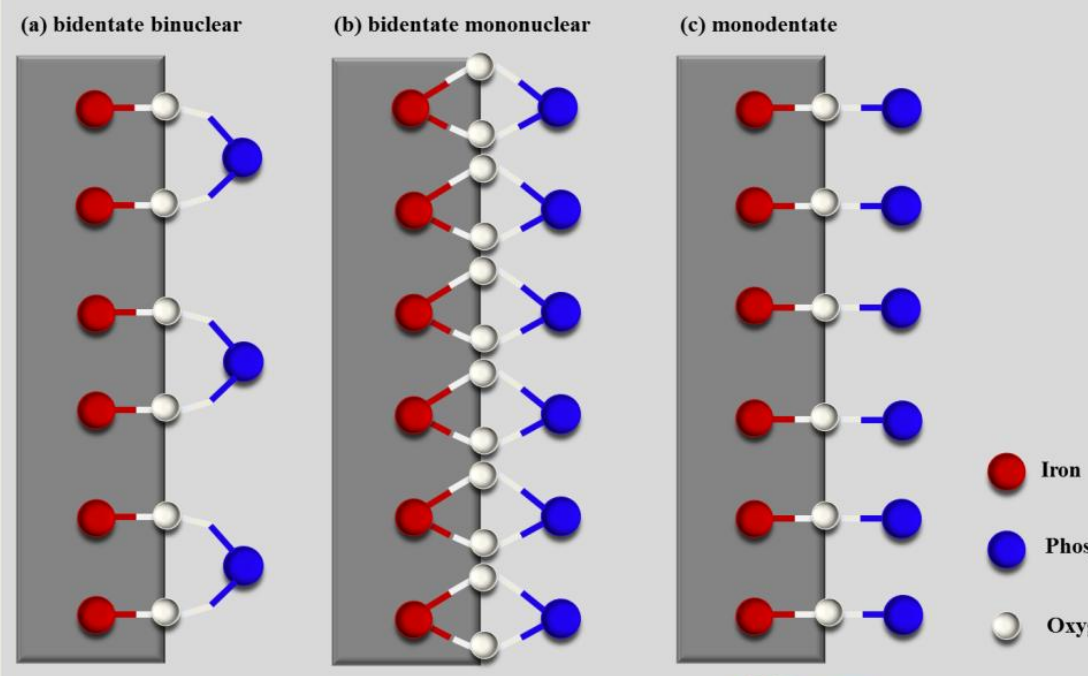

P loading increases 